
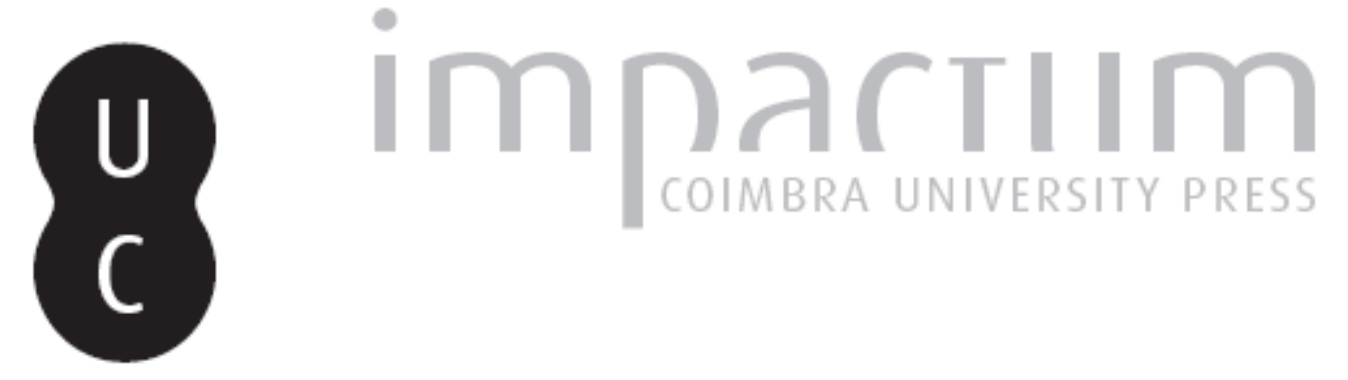

\title{
[Recensão a] PEREIRA, Miriam Halpern, A Primeira República Portuguesa. Na fronteira do liberalismo e da democracia
}

Autor(es): Neto, Vítor

Publicado por: Imprensa da Universidade de Coimbra

URL persistente:

URI:http://hdl.handle.net/10316.2/43838

DOI:

DOI:https://doi.org/10.14195/2183-8925_36_18

Accessed : $\quad$ 26-Apr-2023 14:50:59

A navegação consulta e descarregamento dos títulos inseridos nas Bibliotecas Digitais UC Digitalis, UC Pombalina e UC Impactum, pressupõem a aceitação plena e sem reservas dos Termos e Condições de Uso destas Bibliotecas Digitais, disponíveis em https://digitalis.uc.pt/pt-pt/termos.

Conforme exposto nos referidos Termos e Condições de Uso, o descarregamento de títulos de acesso restrito requer uma licença válida de autorização devendo o utilizador aceder ao(s) documento(s) a partir de um endereço de IP da instituição detentora da supramencionada licença.

Ao utilizador é apenas permitido o descarregamento para uso pessoal, pelo que o emprego do(s) título(s) descarregado(s) para outro fim, designadamente comercial, carece de autorização do respetivo autor ou editor da obra.

Na medida em que todas as obras da UC Digitalis se encontram protegidas pelo Código do Direito de Autor e Direitos Conexos e demais legislação aplicável, toda a cópia, parcial ou total, deste documento, nos casos em que é legalmente admitida, deverá conter ou fazer-se acompanhar por este aviso.

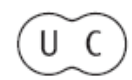



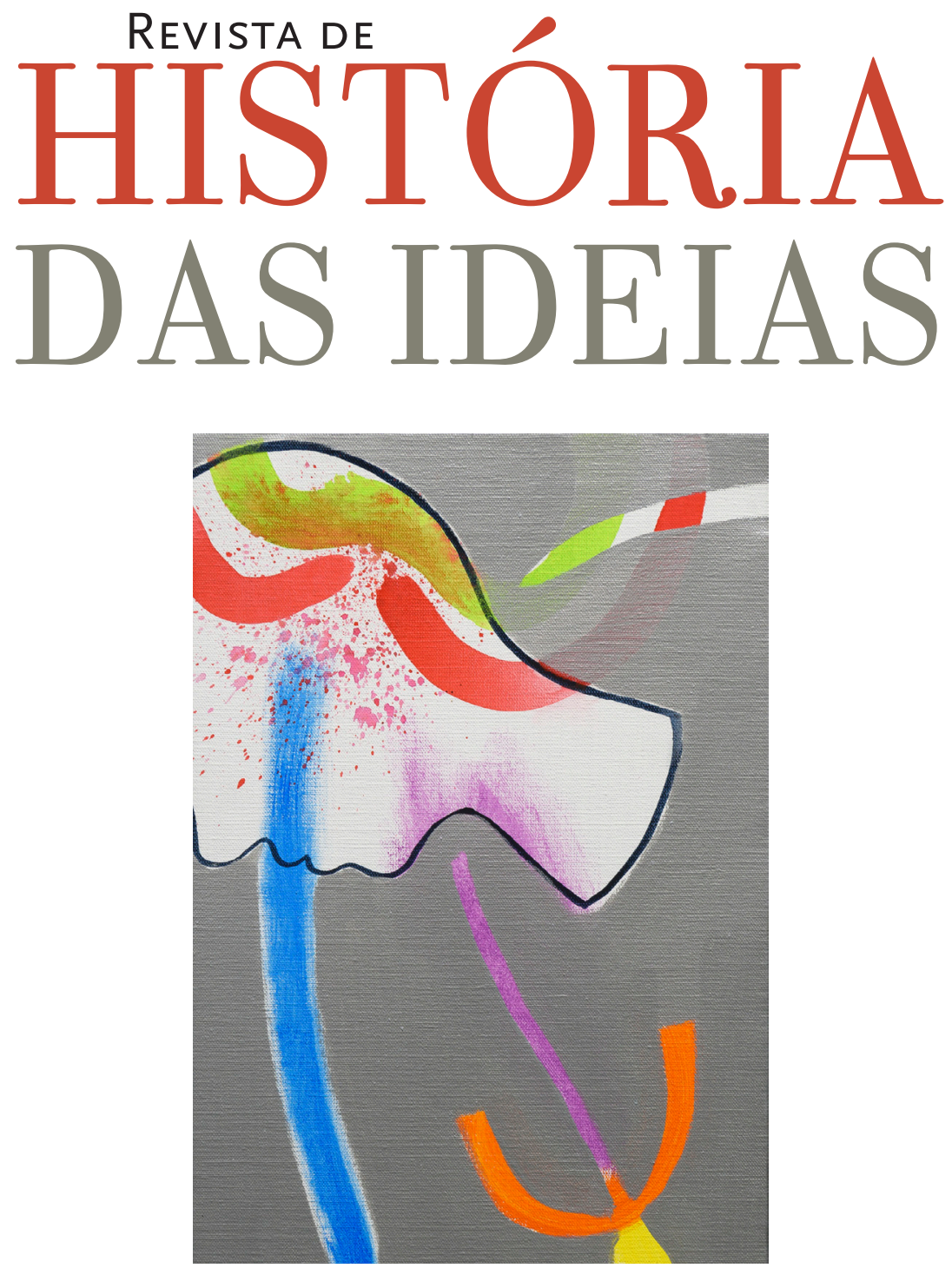

Religiões e Culturas

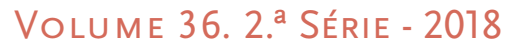


In brief, if one is not yet familiar with Iberian magic and folklore, the book at issue is about one hundred pages too short; the author has left out many points which are fundamental for the accurate interpretation of her sources. Otherwise though, a wealth of rare and precious information can be extracted from this work. Overall, it is an extremely worthy and long overdue addition to the international study of religion, esotericism and magic, and offers some excellent insights into the Iberian magical landscape. Hopefully this book will be the first of many and we will soon be seeing María Tausiet's remaining books follow the same path.

J.VIEIRA LEITÃO
jose.cv.leitao@gmail.com
Universidade de Coimbra, Faculdade de Letras
Orcid.org/0000-0001-7456-5045
https://doi.org/10.14195/2183-8925_36_17

Miriam Halpern Pereira, A Primeira República Portuguesa. Na fronteira do liberalismo e da democracia, Lisboa: Gradiva, 2016, 216 p. ISBN: 9789896167295

O livro de Miriam Halpern Pereira é um estudo interpretativo e sintético sobre a história da Primeira República Portuguesa, definida por muitos historiadores como um regime demoliberal. Não sendo uma obra de investigação, não traz grandes novidades temáticas, mas tem a clareza de um raciocínio límpido, que sabe ler a história com grande maturidade e que vai à procura de novos leitores, não se cingindo a um público meramente universitário. Também não se trata de um mero estudo de divulgação, embora a autora escreva para o grande público. Entrando na «polémica apaixonada» ainda hoje existente sobre a compreensão da República, a autora afasta-se daqueles que continuam a ver o regime como uma fase histórica caracterizada pela «balbúrdia», uma imagem criada pelo Salazarismo, especialmente na sua imprensa; também se distancia do carácter apologético do Regime levado a cabo por outras figuras da nossa historiografia mais republicana e de raiz jacobina. Miriam Pereira afasta-se das duas correntes historiográficas opostas a respeito da I Republica e assume uma posição isenta e objetiva, embora o carácter progressista da sua formação historiográfica não esteja ausente do texto interpretativo que produziu. A seu ver, o regime foi aquilo 
que as conjunturas nacional e internacional lhe permitiram ser e constituiu um momento de avanço da nossa história apenas interrompido pela Ditadura militar de 1926-1932 e do Estado Novo, a partir destes anos. Pelas circunstâncias históricas em que o regime vigorou e dada a conflitualidade existente entre partidos políticos e outras forças sociais, não é, não pode ser, um modelo exemplar a seguir. Apesar disso, a I República portuguesa deixou-nos uma vasta obra legislativa e muitas realizações materiais e imateriais que devem ser objeto da análise sistemática do historiador. Com a entrada na Grande Guerra, iniciou-se uma crise do sistema político, económico e social, tal como se pode constatar através da leitura atenta do livro. Não sendo, como já se disse, um trabalho de investigação científica, a obra revela que a sua autora domina perfeitamente quase toda a bibliografia existente sobre o assunto, incluindo os respetivos textos que cita, ou não, e os artigos inseridos nas Revistas que ela leu. Ora, foi a partir desses estudos e da sua própria reflexão que construiu o estudo que agora saiu a lume. A meu ver, trata-se de um excelente trabalho, que poderá ajudar as novas gerações a conhecer novas modalidades, mais objetivas, com vista a um cabal entendimento da história da Primeira República Portuguesa.

Bem estruturado numa longa introdução de história política, cinco capítulos e múltiplos subcapítulos, o livro de Miriam Halpern Pereira assume uma dimensão globalizante, só faltando um pouco mais de história da cultura para ser uma obra com um objeto total. Começarei por fazer uma incursão pelo interior do conteúdo do livro para retirar, por fim algumas conclusões. A autora, à maneira de introito, escreve um bom texto sobre a história de Portugal durante a Monarquia Constitucional e começa por analisar a narrativa política utilizada no discurso sobre a República, dividindo esta temporalmente em três fases: a «República forte», a «República Nova» e a «Nova República Velha» (ou «República fraca»).

O título da obra parece-me apropriado, embora julgue correto dizer algo acerca dos conceitos de liberalismo e de democracia. Na verdade, o primeiro remete o leitor para todo o longo período da Monarquia Constitucional durante o qual o voto era politicamente censitário, o que significava que só uma parcela menor da sociedade - os cidadãos ativos - votava, ou era eleita. Ora, o liberalismo manteve-se na República, na qual o número de potenciais votantes rondaria apenas os 10\%. Quer isto dizer que, não obstante os esforços republicanos realizados no sentido do alargamento do sufrágio, as votações nas eleições organizadas pelo regime foram muito diminutas. E se, na primeira lei eleitoral, ainda votavam todos aqueles que eram chefes de 
família, ou os que soubessem ler, o voto era masculino. Na lei eleitoral de 1913 (Afonso Costa), as mulheres eram expressamente proibidas de votar, assim como os analfabetos. Por isso, a democracia continuava a ser uma ideia na República, como se pode ler nas páginas deste livro, sem conteúdo real porque, na verdade, o sistema era uma verdadeira oligarquia das capacidades. Desta forma, a República não instituiu a democracia como, aliás, acontecia na quase totalidade dos países do mundo, embora mantivesse esta ideia no seu espírito mais genuinamente utópico.

Na segunda parte da Introdução, Miriam Halpern Pereira, sempre em tom didático, faz uma síntese evolutiva dos Governos e dos Presidentes da República para mostrar como foi uma época instável e politicamente dividida. Refere-se a Teófilo Braga, que de facto não chegou a ser verdadeiramente Presidente da República e que teve uma passagem discreta pelo Governo Provisório, dado que o positivismo que advogava se casava mal com a prática política; destaca muito justamente Manuel de Arriaga e Bernardino Machado, estes sim, verdadeiros presidentes da República, e explica, em síntese, a ação dos diferentes governos até ao Sidonismo, passando pela Ditadura de Pimenta de Castro. Foi o período da «República forte», no qual os governos se sucederam, ao mesmo tempo que as realidades materiais se iam transformando sob o impulso da elite política. Isto sem omitir a divisão do velho Partido Republicano Português em outras organizações: o Partido Democrático de Afonso Costa, o Partido Evolucionista de António José de Almeida e o Partido Unionista de Brito Camacho. Neste trecho, convém lembrar que a historiadora nos ajuda também a compreender o papel dos Monárquicos e das suas incursões em território nacional, a partir da Galiza. Depois de fazer uma referência significativa ao Presidencialismo de Sidónio Pais e aos 10 meses em que ele se manteve no poder antes de ser assassinado (em 14 de dezembro de 1918) por José Júlio, um ex-sindicalista rural, a historiadora aborda a Monarquia do Norte, a gripe pneumónica, o anarco-sindicalismo e o socialismo, para se deter nas presidências de Canto e Castro, António José de Almeida, Teixeira Gomes e Bernardino Machado. É a «República fraca», que é passada em revista com os seus maiores acontecimentos políticos, como a «Noite Sangrenta» ou as divisões e fusões dos partidos.

Sempre numa escrita fluente e fácil de ler, embora trate de assuntos complexos, Miriam Pereira escreve um excelente capítulo sobre a laicização como projeto cultural da República. A historiadora usa muito bem obras como as de Fernando Catroga sobre o assunto, para esclarecer temas como o da laicização e o do anticlericalismo, do Estado e da religião e da Lei da 
Separação entre o Estado e as Igrejas. Miriam Halpern Pereira é uma boa conhecedora desta dimensão da realidade, indo à sua raiz - a secularização oitocentista que funcionou como primeiro passo para a rutura entre a religião e a política que viria a ocorrer em 1911, como veremos. Na realidade, ao longo da segunda metade do século XIX, foi-se afirmando a laicidade como programa político-cultural que viria a ser concretizado com a publicação da legislação republicana em matéria religiosa, a qual teria como vértice a Separação entre o Estado e as Igrejas decretada por Afonso Costa em 20 de abril de 1911. E se o Estado se separava das Igrejas, uma conquista civilizacional presente nos nossos dias, o poder civil, segundo a nossa historiadora, também se separava da escola e fazia da educação a fonte da formação da cidadania. Daí que a autora se demore a explicar, sempre com um sentido pedagógico apurado, as reformas da República para os ensinos primário, secundário e universitário. Deste modo, valorizou o papel dos republicanos nesta área, como seria de esperar de uma historiadora que aborda a República de uma maneira séria, distinguindo-se daqueles historiadores de direita que apenas vêm nela uma época de conflitos, de lutas, de revoltas e de revoluções.

Segundo Miriam Halpern Pereira, a República foi também o tempo da formação da cidadania, apesar dos limites que a escola teve na educação e no combate ao analfabetismo. A historiadora fala-nos da nova elite política, do Exército e das armas como lugar de formação da cidadania, da criação da G.N.R., do Exército e da Marinha, e da importância que a República teve para o seu desenvolvimento. Ainda neste capítulo, tece várias considerações certeiras sobre as relações laborais e desenvolve o tema do feminismo, evocando os nomes das feministas mais destacadas nas lutas pelas igualdades sociais. Nesse ensejo, realça a Liga Portuguesa para a Paz (1906) e a criação, no ano seguinte, do Grupo Português de Estudos Feministas, uma iniciativa de Ana de Castro Osório, Adelaide Cabete, Carolina Beatriz Ângelo e Maria Veleda. Em 1908, de acordo com a historiadora, o grupo dissolveu-se e foi criada a Liga Republicana das Mulheres Portuguesas (LRMP), formada com o apoio de líderes republicanos como António José de Almeida, Bernardino Machado e Magalhães Lima; a História veio a mostrar a cisão da Liga e a formação de outros Grupos. Tudo isto tem vindo a ser estudado por historiadores que assumem como um dos objetos da sua investigação o tema das Mulheres. Cabe aqui uma referência a Angelina Vidal, uma professora que se dedicou, através da escrita e dos comícios políticos, à defesa da mulher operária, tendo pertencido ao Partido Operário Socialista. Para falarmos de Angelina Vidal, temos de deixar de fora outras mulheres destacadas, 
como Matilde Simes, Eugénia Maia e mais algumas dezenas de filiadas na União das Mulheres Socialistas. Angelina Vidal teria sido uma excelente jornalista e, no seu maior radicalismo, Maria Veleda destacou-se na defesa da «mulher do povo».

Num dos capítulos, Miriam Pereira escreve sobre o espaço público e cívico, tão importante durante a República que o laicizou. Para isso, teria contribuído a imprensa que formou a opinião pública e a escola que moldou a consciência do cidadão demo-liberal. Estas eram duas questões essenciais que expressavam a difusão de um discurso profano oposto ao discurso sagrado divulgado pelas Igrejas. Na criação desta nova mundividência dessacralizada, destacaram-se os jornais, a imagem e a rádio. Havia periódicos ligados a partidos: O Mundo, a Lucta, A República, assim como jornais ligados aos Sindicatos e uma imprensa articulada com os meios económicos (exs.: O Século e o Diário de Notícias); para além disso, a historiadora fala de jornais como o Primeiro de Janeiro, no Porto. Ligados ao Centro Católico Português e à Causa Monárquica encontravam-se a União e a Época. Em 1923, seria criado o jornal Novidades, órgão de imprensa com uma longa história posterior. Nas margens do poder, socialistas, anarquistas e - mais tarde - os comunistas que, saídos do anarco-sindicalismo, criaram o seu próprio partido em 1921 (P.C.P.) a partir da Federação Maximalista Portuguesa (FMP), e lutaram por uma «República Social» oposta à ordem e à autoridade da Igreja Católica. Miriam Halpern Pereira afirma que esta fase foi o momento do desenvolvimento do associativismo. Na realidade, foram criadas as associações patronais para defender os interesses de classe e a elas puderam opor-se as associações operárias e as dos sindicatos, numa fase de forte conflitualidade como o foi a fase final da Primeira República. Para além disso, a época também exprimiu o protesto popular e outras formas de sociabilidade que tanta importância tiveram, tais como o mutualismo, que ultrapassava mesmo os sindicatos nesta vertente. E, como não podia faltar numa historiadora que privilegiou os estudos das infraestruturas ao longo da sua carreira de historiadora, escreve um belo capítulo sobre economia e finanças, que antecede um outro sobre o Império e a emigração, dois fatores intimamente ligados. Na verdade, a I República conseguiu conservar as colónias durante o pós-guerra, ao mesmo tempo que promoveu uma política de emigração, especialmente para o Brasil mas também para as colónias, a qual contribuiu para ajudar a equilibrar o défice.

Por fim, trata-se de um livro que não me levanta objeções, faltando talvez realçar um pouco mais o papel do movimento operário, embora a autora o 
explique. De uma maneira geral, estou de acordo com o seu conteúdo, bem expresso através de uma linguagem apropriada. Historiadora de vastos recursos, Miriam Halpern Pereira vai do político ao económico com grande facilidade, e deste ao social. Talvez a obra merecesse um capítulo sobre a cultura na República (Saudosismo, Modernismo, Integralismo Lusitano), a qual, não sendo muitas vezes assumidamente republicana, também faz parte da história do regime.

Os historiadores, os alunos e o grande público precisam muito de boas sínteses interpretativas sobre períodos já muito estudados mas sobre os quais faltam, por vezes, trabalhos que condensem os conhecimentos, cingindo-se à objetividade e à cientificidade. Ora, em virtude do seu perfil intelectual e profissional, da sua experiência e do seu saber, Miriam Halpern Pereira escreveu um livro feliz pela clareza da sua escrita, que «apenas» traduz um pensamento de extraordinária maturidade, muito saber e apaixonado pela História. Esse «gosto» por esta Ciência Social apenas se pode ler nos interstícios das suas páginas, pois a sua preocupação-chave é a transmissão de um conhecimento que, como já referimos, se revela tão objetivo quanto possível, sem preconceitos, progressivo e, por isso mesmo, mais verdadeiro. Como se conclui do seu livro, a República não foi um simples parêntesis da história, entalado entre a Monarquia Constitucional e o Estado Novo. Não, o regime configurou-se num sistema político, económico e social próprio, com a sua originalidade a vir, até certo ponto, do passado, mas estando também voltada para o futuro. Foi, como já se disse, um regime num tempo de utopias interrompidas pela tirania do ditador Oliveira Salazar, o qual, formando-se nela, tudo fez para a destruir, assim como aos seus dirigentes máximos.

Em síntese final, creio poder afirmar que o livro de Miriam Halpern Pereira é uma lufada de ar fresco surgida no interior das lutas mais ou menos apaixonadas e nas polémicas melhor ou pior expressas sobre o objeto da I República. Trata-se assim, a meu ver, de um trabalho sólido, baseado nos conhecimentos profundos que a autora tem do tema, escrito com lucidez e inteligência e apoiado numa metodologia rigorosa. Desta forma, a historiadora coloca a República no seu devido lugar. Longe das inflamações apologéticas de um setor republicano mais radical e, por outro lado, distante da visão de direita que muitos historiadores ainda hoje usam para nos fornecer a sua explicação sobre a República. É por isso, e conforme foi explicado, um trabalho isento e exemplar sob o ponto de vista 
epistemológico. Só é pena que a autora não pudesse ter ido ir mais além no recurso a uma bibliografia mais exaustiva, que ela não cita, ou refere apenas de uma forma breve.

\author{
VÍTOR NETO \\ vitormpneto@sapo.pt \\ Professor da FLUC
}

Orcid: 0000-0002-1713-9901

https://doi.org/10.14195/2183-8925_36_18

João Filipe Queiró, O Ensino Superior em Portugal, Lisboa, Fundação Francisco Manuel dos Santos (Ensaios da Fundação), 2017, 96 p. Depósito Legal n. ${ }^{\circ}$ 429 992/17. ISBN: 9898863293

Aos estudantes e professores, a universidade não dá conforto, dá-lhes tempo, o tempo longo e necessário ao estudo escrupuloso e ao desenvolvimento pessoal. (p. 18)

Estas palavras constituem apenas uma das muitas epígrafes que poderiam ajustar-se ao ensaio que João Queiró escreveu sobre o Ensino Superior em Portugal, recentemente publicado na já extensa e inestimável coleção de Ensaios da Fundação Francisco Manuel dos Santos.

De facto, a apologia do saber que se adquire de forma lenta, persistente, sólida, longe de distrações (tecnológicas ou outras) traduz apenas um dos pontos fortes que sustentam o pensamento do autor.

A obra em apreço integra-se plenamente no género a que pertence, ou seja, assume-se como verdadeiro ensaio, veiculando posições claras que contrariam algumas tendências dominantes. Por detrás da sua aparente simplicidade, a citação que acima se transcreve remete, desde logo, para ideias de vasto alcance, defendendo as noções de «tempo longo», «estudo escrupuloso»e «desenvolvimento pessoal» (e não apenas académico). Ora, sabemos bem como essas posições são hoje postas em causa em nome de ritmos de aprendizagem bem mais céleres e, sobretudo, em nome de uma lógica de produtividade estritamente quantitativa. 